\title{
Astrobiological applications of $\mu$ - mapping X-ray Fluorescence Spectroscopy on Earth and Mars
}

DAVID BLAKE ${ }^{1 *}$, RICHARD WALROTH ${ }^{2}$, THOMAS BRISTOW ${ }^{1}$, PHILIPPE SARRAZIN ${ }^{3}$, MARC GAILHANOU ${ }^{4}$, ROBERT DOWNS ${ }^{5}$ AND KATHLEEN THOMPSON ${ }^{3}$

NASA ARC, Moffett Field, USA (*correspondence:

david.blake@nasa.gov)

${ }^{3}$ SSRL, Stanford, CA USA

${ }^{3}$ SETI Institute, Mountain View, CA USA

${ }^{4}$ Aix Marseille Université, CNRS, IM2NP, Marseille, FR

sUniversity of Arizona, Tucson, AZ

The search for evidence of life or its processes, whether on Earth or on other worlds follows two major themes: 1), the identification of environments that have or once had the potential to harbor life (habitability); and 2), the detection of morphological or chemical features suggestive of extinct or extant life (biosignatures). Elemental imaging is invaluable in either case.

Compositional heterogeneity at the $\mathrm{mm}$ to $\mu \mathrm{m}$ scale can reveal geological processes indicative of past or present habitability, and morphological and compositional heterogeneity on a similar length scale can provide evidence of life's processes. The Mapping X-ray Fluorescence Spectrometer (MapX) is an in-situ instrument designed to identify these features on planetary surfaces [1].

Progress on instrument development, data analysis methods, and element quantification are presented, illustrated by astrobiologically relevant examples from MapX $(\sim 100 \mu \mathrm{m}$ lateral resolution) and a commercial EDAX Orbis $\mu$-XRF spectrometer ( $\sim 30 \mu \mathrm{m}$ lateral resolution). MapX and EDAX data are evaluated on the basis of X-ray diffraction, optical petrography and electron microprobe analysis.

[1]. Walroth, R.C. et al. (2019). LPSC 50, Abstr. \# 1616. 